\title{
A Case of Acute Fronto-Ethmoido-Orbital Mucocele
}

\author{
${ }^{1}$ Vivek Sasindran, ${ }^{2}$ Antony Joseph, ${ }^{3}$ Sabah Moosankutty, ${ }^{4}$ Amol Gautam
}

\begin{abstract}
Mucoceles are thought to arise as a consequence of obstruction and inflammation. Frontoethmoidal mucocele can present with multiple symptoms that also include ophthalmic symptoms. Though benign, they have the tendency to expand by thinning the bony walls, displace and invade the surrounding structures by pressure and bony erosions. When it involves the orbit and expands, it may mimic benign growths primarily arising from orbit. We report an acute presentation of fronto-ethmoidoorbital mucocele as a result of hemorrhage into the mucocele.
\end{abstract}

Keywords: Frontoethmoidal mucocele, Proptosis, Orbital decompression.

How to cite this article: Sasindran V, Joseph A, Moosankutty S, Gautam A. A Case of Acute Fronto-Ethmoido-Orbital Mucocele. Clin Rhinol An Int J 2014;7(3):121-124.

\section{Source of support: Nil}

Conflict of interest: None

\section{INTRODUCTION}

A mucocele is an epithelial lined, mucus containing sac completely filling the sinus and capable of expansion. ${ }^{1,2}$ This is in contradiction to a blocked sinus which simply contain mucus. ${ }^{2,3}$ Frontoethmoidal sinus is more susceptible to mucocele formation (89\%) due to complexity of its drainage and maxillary sinus being the least affected $(1 \%)^{2}$

A mucocele is formed when drainage of mucus from one of the paranasal sinuses becomes blocked by obstruction of its ostium and inflammation. Once blockage of the ostium occurs, pressure develops within the affected sinus as the amount of mucus increases within it. This in turn causes a slow expansion of the sinus space, with subsequent thinning, bony erosion and displacement of bone and expansion initiated by infection. Eventually encroaching upon contiguous structures, including

\footnotetext{
${ }^{1,4}$ Associate Professor, ${ }^{2}$ Professor and Head

${ }^{3}$ Postgraduate Resident

${ }^{1-3}$ Department of ENT, Pushpagiri Institute of Medical Sciences and Research Centre, Tiruvalla, Kerala, India

${ }^{4}$ Department of Radiodiagnosis, Pushpagiri Institute of Medical Sciences and Research Centre, Tiruvalla, Kerala, India

Corresponding Author: Vivek Sasindran, Associate Professor, Department of ENT, Pushpagiri Institute of Medical Sciences and Research Centre, Tiruvalla-689101, Kerala, India Phone: 9947132343, e-mail: sabahstarz@gmail.com
}

the optic nerve, oculomotor nerves and the extraocular muscles. ${ }^{1,4}$ Although such mucoceles originate in the paranasal sinuses, they are usually only associated with ophthalmic and not rhinologic symptoms. ${ }^{4}$

The occlusion of ostium may be secondary to congenital anomalies, allergy, osteomas, scarring, polyp or trauma. Frontoethmoidal mucocele usually presents with outward and downward displacement of orbital globe and is often associated with palpable mass in superonasal and medial canthal region. ${ }^{5}$ The main objective of this case is to report an acute presentation of fronto-ethmoidoorbital mucocele.

\section{CASE REPORT}

A 49-year-old female patient presented with sudden onset of proptosis, pain around the right eye and right sided frontal headache for 3 days. Periorbital edema, lid edema, chemosis, epiphora and localized tenderness were present. On examination, she had restricted eye movements with diplopia (Fig. 1). Pupils were reactive, with visual acuity of $6 / 12$ and normal color vision. Fundoscopic examination revealed minimal papilledema. Anterior rhinoscopy showed remnants of middle turbinate on the right side and posterior septal defect. She underwent functional endoscopic sinus surgery 6 years back. Postoperative period was uneventful.

On computed tomography (CT) scan of nose and paranasal sinuses, there was well defined hypodense lesion seen adjacent to medial and superior aspect of the right orbit with areas of hyperdensity (Fig. 2). The lesion had well defined inferior margin with clear separation noted between the lesion and the globe. There was extension of this lesion to ethmoidal and frontal sinus. There was erosion of the lamina papyracea of the orbit (Fig. 3), dehiscence of anterior ethmoidal artery and posterior septal defect. Post contrast study did not show any area of enhancement, suggestive of cystic lesion within the hemorrhage (Fig. 4). Magnetic resonance imaging (MRI) of orbit showed well defined $\mathrm{T} 2$ hyperintense lesion with signal intensity of fluid in the supraorbital region of right orbit with clear communication with the right frontal sinus and mass effect of the right orbit in inferolateral direction with inferior displacement of superior rectus, medial rectus and proptosis (Fig. 5). In T2 axial flair, there was complete suppression of T2 hyperintensity, most probably suggestive of mucocele. T1 sagittal image 


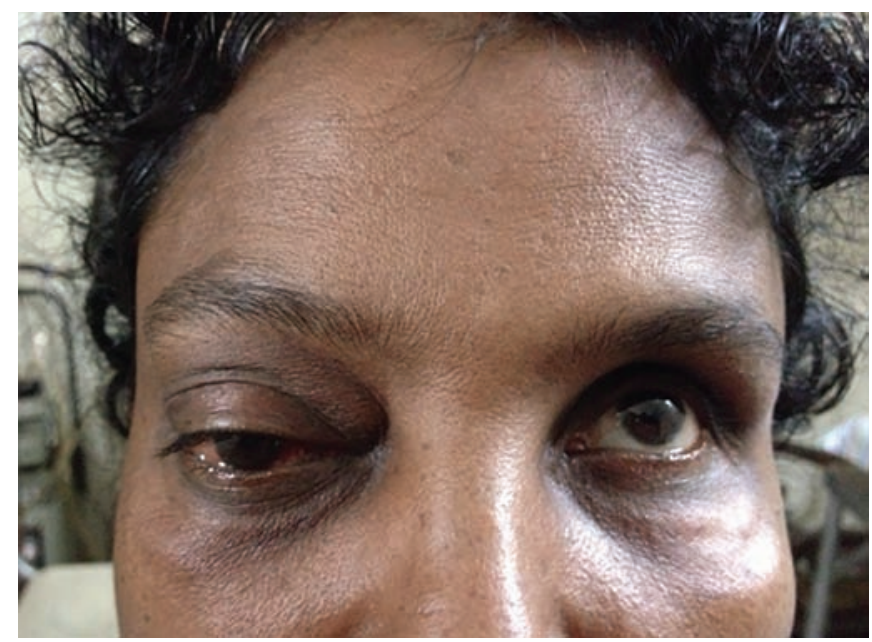

Fig. 1: Preoperative photograph

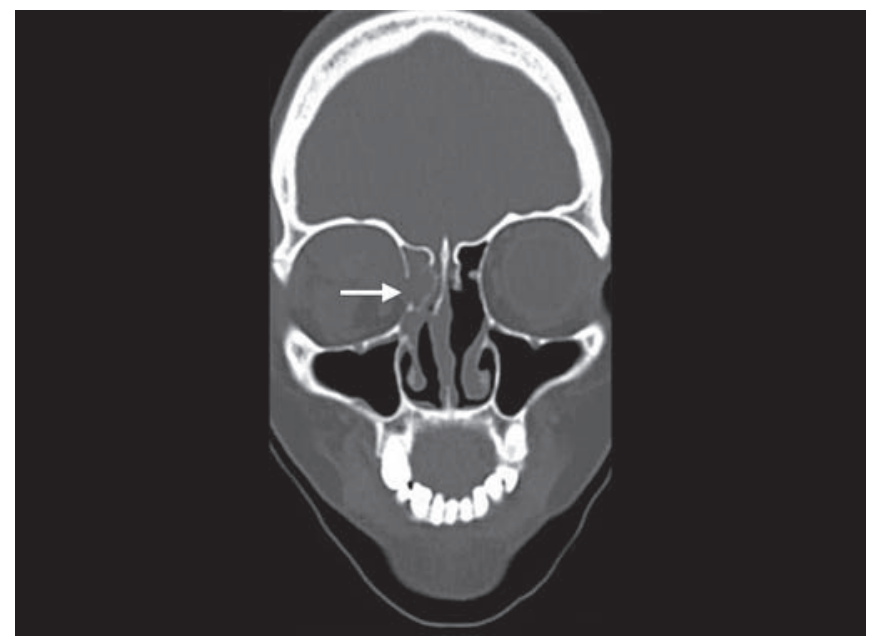

Fig. 3: CT (Coronal bone window setting) defect in right lamina papyracea is demarcated by arrow with communication of ethmoidal collection to intraorbital collection

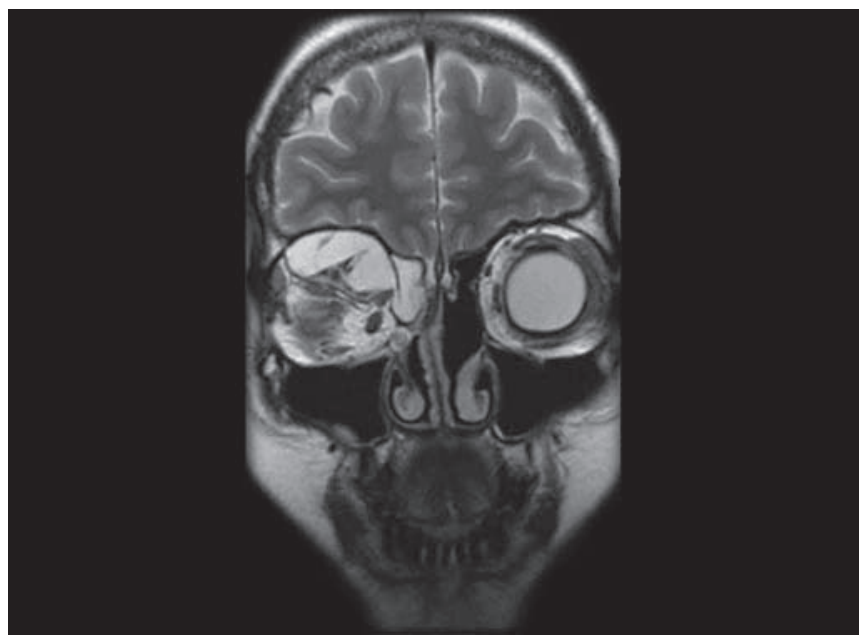

Fig. 5: MRI (T2w coronal) TR: $4120 \mathrm{msec}, \mathrm{TE}: 86.6 \mathrm{msec}$ $\mathrm{T} 2 \mathrm{w}$ hyperintense collection seen in extraconal superomedial compartment of right orbit, communication with right anterior ethmoidal air cells collection through dehiscence of lamina pap

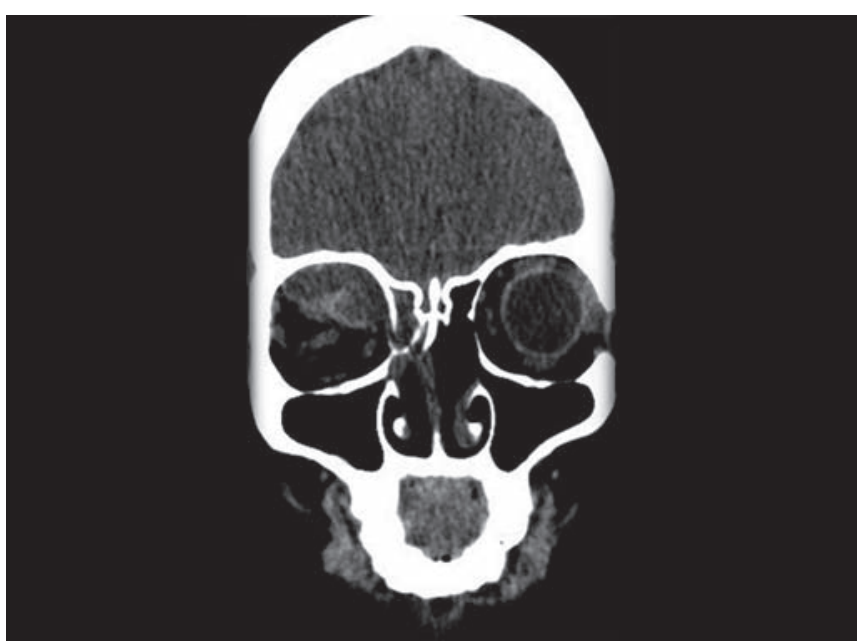

Fig. 2: CT (Coronal soft tissue window setting) focal collection in intraorbital retroglobal compartment superomedially with hyperintense areas within-s/o hemorrhage

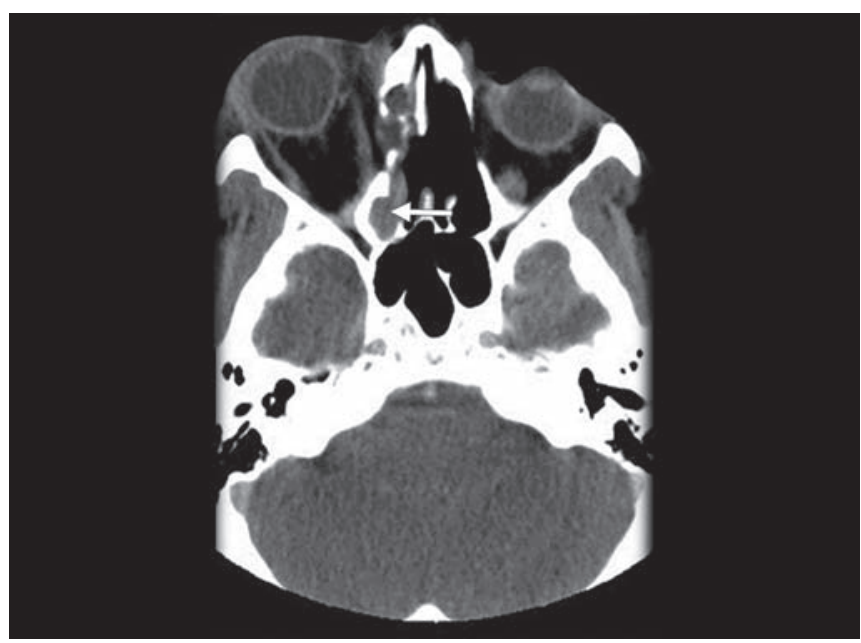

Fig. 4: CT (Axial soft tissue window setting) post contrast $A$ branch of anterior ethmoidal artery seen within right anterior ethmoida collection as enhancing focus (marked by arrow). Intraorbital and right fronto-anterior ethmoidal mucocele do not enhance

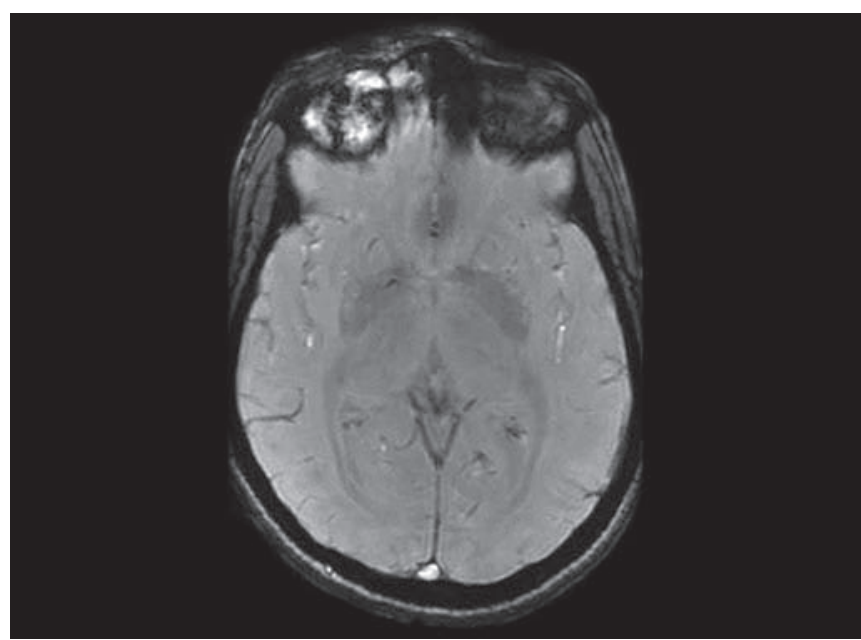

Fig. 6: MRI (SWAN sequence: 3D SWAN TR: $79.3 \mathrm{msec}$, TE: 50.0 msec) Linear areas of blooming on 3D gradient sequence-s/o hemorrhage within intraorbital collection 


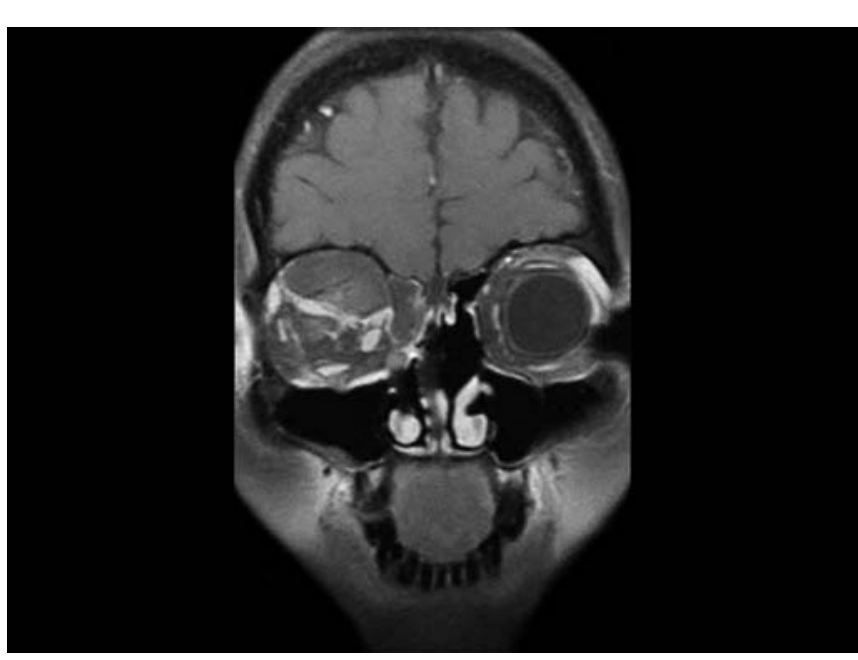

Fig. 7: MRI (post contrast T1w fat sat coronal) TR: $1240 \mathrm{msec}$ TE: $11.8 \mathrm{msec}$ no enhancement seen within right orbital collection - $\mathrm{s} / \mathrm{o}$ mucocele

showed peripheral rim of hyperintensity which showed areas of blooming, suggestive of hemorrhage (Fig. 6). Post contrast fat suppressed T1 did not show any intense enhancement within it (Fig. 7).

Revision functional endoscopic sinus surgery with medial orbital decompression was planned. On table middle turbinate remnant was seen attached to the lateral wall obstructing the frontal drainage pathway. Adhesion between the turbinate remnant and lateral wall was separated and the contents of mucocele could be drained out. Drilling over the frontal process of maxilla and lacrimal bone was carried out anteriorly and laterally to gain a wide access to the frontal recess region. Dehiscence in the lamina papyracea and anterior ethmoidal artery were identified. Contents of mucocele could be tracked all the way to the superior orbital region after deroofing the lamina papyracea keeping the periorbita intact, thus completing the medial orbital decompression. Bleeding from anterior ethmoidal artery was cauterized close to the periorbita. Peroperatively, thick tenacious yellowish mucosal content was seen with blood clots in the superior aspect of the orbit, suggestive of hemorrhage within the mucocele. Complete ethmoidectomy and sphenoidotomy were carried out. Postoperatively, there was complete resolution of swelling with improvement of proptosis, diplopia and eye movements (Fig. 8).

\section{DISCUSSION AND CONCLUSION}

The term mucocele was introduced by Rollet in 1896 and the first histopathological description was made by Onodi in 1901. Mucocele is formed when drainage of mucus from one of the paranasal sinuses becomes blocked by obstruction of its content as a result of inflammation, trauma or repeated surgery in and around the nasal cavity and adjacent sinuses. ${ }^{6,7}$

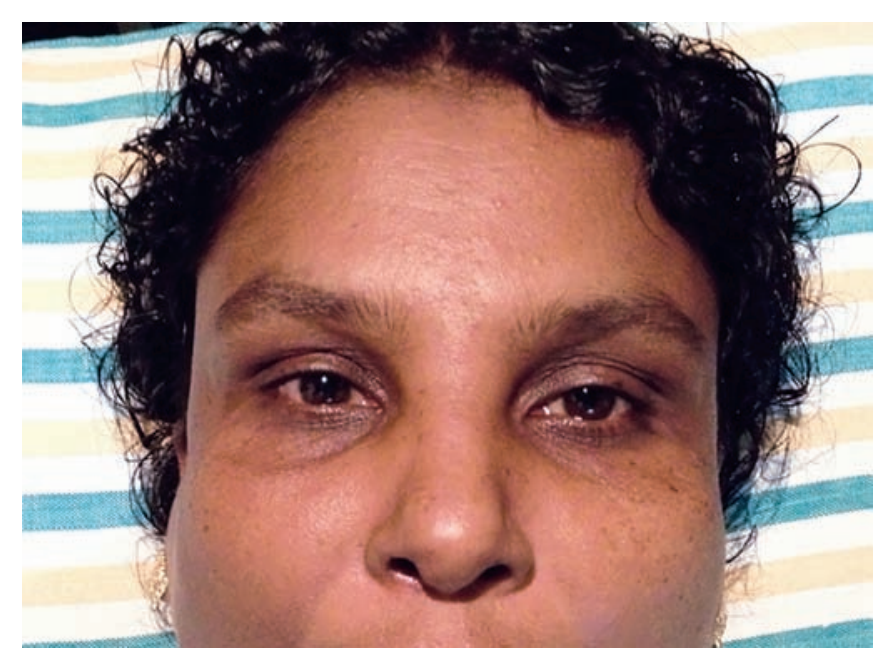

Fig. 8: Postoperative photograph

There may be a considerable time lag between the initiating factor and clinical presentation. In the case of surgery or trauma, there is an average of 23 years, whereas following an acute infection the mean time of presentation is 22 months. ${ }^{2}$ It may occur rapidly when it is secondarily infected producing a pyocele or mucopyocele. In our case, mean time of presentation of mucocele following surgery was 6 years with signs and symptoms presenting in 3 days.

Three main theories of pathogenesis include pressure erosion, cystic degeneration of glandular tissue and active bone resorption and regeneration. A number of bone resorbing factors are found in mucocele mucosa like PGE2, leukotrienes, hydroxyeicosatetraenoic acids (HETES) and range of cytokines that activates osteoclasts. ${ }^{2,8}$ Increased levels of IL-1a, IL-1b and tumor necrosis factor- $\alpha$ (TNF- $\alpha$ ) together with upregulation of vascular adhesion molecules, e-selectin and intercellular adhesion moleculel-1 (ICAM-1) are found in mucocele lining when compared to normal controls. In normal situation, new bone formation is balanced by osteolysis. ${ }^{2,9}$ In mucocele, balance is just tipped in favor of osteolysis facilitating expansion of lesion. Mucoceles are relatively uncommon and rarely bilateral $(<5 \%)^{2}$

The expansion of mucocele generally follows the route of least resistance into the orbit, with frontoethmoidal mucocele presenting with proptosis (1-17 $\mathrm{mm})$ : $91 \%$, lateral displacement (2-13 mm): $55 \%$, inferior displacement (1-8 mm): $59 \%$, diplopia (vertical): $95 \%$, limited ocular mobility: $55 \%$ and reduced visual acuity: $9 \% .^{2}$ In our case, there was no expansion of sinus or bone erosion. Mucocele-tracked through the path of least resistance formed by the preformed pathway, i.e. through the dehiscence in the lamina papyracea into the supraorbital region. Acute presentation was a result of bleeding from anterior ethmoidal artery which was dehiscent. 
Computed tomography is the preferred mode of imaging as it gives evidence of bone involvement, assesses intracranial and/or orbital extension and supports surgical planning. On CT scan, the mucocele usually appears as homogenous, low density, nonenhancing soft tissue masses causing expansion of the involved sinus and erosion of the adjacent orbital walls with protrusion of mass into the orbit. ${ }^{2,10}$ Several treatment options are available and choice depends on the degree of extension. It may range from functional endoscopic sinus surgery to external approach, craniotomy and craniofacial exposure with or without obliteration of the sinus. ${ }^{11}$ The current trend is to conduct functional, minimally invasive and low morbidity procedure with sinonasal endoscopic surgery with marsupialization. ${ }^{12}$ In our case, mucocele was endoscopically managed achieving a wide patency of the frontal sinus drainage pathway so as to reduce the chance of recurrence along with medial orbital decompression to address the orbital component of mucocele.

\section{REFERENCES}

1. Natvig K, Larsen TE. Mucocele of the paranasal sinuses: a retrospective clinical and histological study. J Laryngol Otol 1978 Dec;92(12):1075-1082.

2. Lund VJ. Mucocele (119). Scott-Brown's otorhinolaryngology, head and neck surgery. 7th ed. London: Hodder Arnold; 2008. p. 1531-1538.
3. Schenck NL, Rauchbach E, Ogura JH. Frontal sinus disease. II. Development of the frontal sinus model: occlusion of the nasofrontal duct. Laryngoscope 1974 Jul;84(7):1233-1247.

4. Tseng CC, Ho CY, Kao SC. Ophthalmic manifestations of paranasal sinus mucoceles. J Chin Med Assoc 2005 Jun; 68(6):260-264.

5. Molteni G, Spinelli R, Panigatti S, Colombo L, Ronchi P. Voluminous frontoethmoidal mucocele with epidural involvement. Surgical treatment by coronal approach. Acta Otorhinolaryngol Ital 2003 Jun;23(3):185-190.

6. Chiarini L, Nocini PF, Bedogni A, Consolo U, Giannetti L, Merli GA. Intracranial spread of a giant frontal mucocele: case report. Br J Oral Maxillofac Surg 2000 Dec;38(6):637-640.

7. Hurley DB, Javer AR, Kuhn FA, Citardi MJ. The endoscopic management of chronic frontal sinusitis associated with frontal sinus posterior table erosion. Am J Rhinol 2000 MarApr;14(2):113-120.

8. Lund VJ, Harvey W, Meghji S, Harris M. Prostaglandin synthesis in the pathogenesis of frontoethmoidal mucoceles. Acta Otolaryngol 1988 Jul-Aug;106(1-2):145-151.

9. Lund VJ, Henderson B, Song Y. Involvement of cytokines and vascular adhesion receptors in the pathology of frontoethmoidal mucocoeles. Acta Otolaryngol 1993 Jul;113(4):540-546.

10. Kennedy DW, Josephson JS, Zinreich SJ, Mattox DE, Goldsmith MM. Endoscopic sinus surgery for mucoceles: a viable alternative. Laryngoscope 1989 Sep;99(9):885-895.

11. Weitzel EK, Hollier LH, Calzada G, Manolidis S. Single stage management of complex fronto-orbital mucoceles. J Craniofac Surg 2002 Nov;13(6):739-745.

12. Lund VJ. Endoscopic management of paranasal sinus mucoceles. J Laryngol Otol 1998 Jan;112(1):36-40. 